\title{
Irrational thoughts of the translator's personality in assessing the quality of translation
}

\author{
Jabbar Frayyeh Shraida ${ }^{1}$, Muthana Hameed Khalaf ${ }^{2}$ \\ ${ }^{1}$ Psychological Research Center, Ministry of Higher Education, Iraq \\ ${ }^{2}$ College of Science, University of Baghdad, Iraq
}

\section{Article Info \\ Article history: \\ Received Feb 8, 2020 \\ Revised Sep 24, 2020 \\ Accepted Oct 11, 2020}

\section{Keywords:}

Irrational ideas

Psychological challenges

Translation

Translator's personality

\begin{abstract}
The correlation between translation as an objective field and psychological characteristics has produced various psychological and translational interrogations. To investigate the role of the translator's personality in identifying the level of irrationality beliefs, university instructors are the corpus of the present study. After using statistical means SPSS, the results of instructors of males and females were observed to advocate for an active role of the translator in some instances. The present study employed a questionnaire that is consisted of thirty-five paragraphs measures the individual's attitude towards himself and his or her family that behaves irrationally in the performance and functions. Through the results of this study, which this study found that irrational thoughts are widespread among male and female teachers. This research also provided details of making an empirical contribution to the research in translation. Thus, the seriousness of irrational thoughts, as it is one of the reasons for the incompatibility and its seriousness on translation. This led to the weakness of the translation process, which caused the distraction of the mind to broadcast the hostile rumour that managed to exploit confusion in the translation.
\end{abstract}

This is an open access article under the CC BY-SA license.

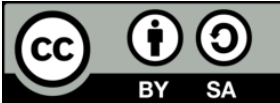

\section{Corresponding Author:}

Jabbar Frayyeh Shraida, Psychological Research Center, Ministry of Higher Education, Iraq.

Email: jabbar.alami@yahoo.com

\section{INTRODUCTION}

Many studies have been made to identify the distinctive qualities of translation that it is necessary to ascertain the most important traits of the cognitive processes of the translation operation [1]. Whatever qualities one manages to comprise in the psychological profile of the translator, they are likely to be of value in many other disciplines as playing a vital role in the study of translation [2]. The relationship between translation and psychology has developed considerably because psychology is an essential part of the study of translation [3]. This paper sheds light on the psychological challenges such as irrational thoughts that are likely to be encountered in English-Arabic-English translation and factors that may finally lead to a theory of it.

Irrational beliefs develop individually since early childhood. The child is sensitive to the influences of the external environment and more suggestive at the childhood stage. He depends on others, especially parents in the planning, thinking and decision-making. If some family members sometimes are rational, they believe in superstition. They tend to intolerance and demand their children to achieve goals and aspirations that do not reach their potential, leading to the child becoming irrational [4]. The psychological aspects, such 
as irrational thoughts that are relatable in the translation career comprise high awareness that consequently affects their translations in educational institutions.

Measuring the Irrational thoughts among Iraqi university instructors for many reasons include some circumstances in Iraq such as the wars and dictatorship for forty years, the siege, low level of education, corruption in the general and psychological collapse of all segments of society, which reflected on the culture of the university instructors so that it affected by the circumstances surrounding it. Our Arab community in general, and Iraq in particular, have been subjected to violent shocks over the past years by the successive wars and the accompanying economic blockade, which has misled the value system of individuals and left a clear imprint on their behaviour on the moral, social and psychological level. Therefore, the individuals were weakened by psychological and non-normative tranquillity [5]. It should be noted that irrational thoughts are not stable; they are subjected to change. Professional experiences may raise or lower rates [2]. Refer to irrational thoughts that are not due to find empirical support and reflect duties and orders, for example, I must be well-received and accepted; otherwise, and they will be considered corrupt. These thoughts are often severe emotional disorders such as neuroleptic psychosis and others.

The human beings are the only creature that God Almighty singled out by the grace of thinking. This thinking man can be the successor of God in the earth, deserve the grace of God Almighty, and seek to use the ideas to set goals and strive to achieve them. Specific goals may prevent the achievement of these goals, it is annoying, and among the beliefs held by individuals about these events reflected feelings and behaviours emanating from them. It seems that events do not create feelings, but beliefs about these events that contribute to the formation and manifestation of attitudes specifically [6]. Human beings tend to be innately subjected to influence, especially during childhood. This influence is from family members of their immediate peers, as well as by the civilized environment in which they live in general. Although there are vast differences between individuals in this area, human adds to his disorder emotional and irrational submission to family and community education and traditions [7].

The present study looks for the psychological features which affect the translation process to increase the quality of translation. Indeed, individual characteristics like the translator's knowledge, experience, personality, and different skills that the translator rationales in the translation influence translation quality [8]. The pattern of ideas of a translator about the events and experiences is the fundamental variable in determining his behavioral and emotional responses. If the pattern of his ideas is rational, he will translate effectively and productively. If the pattern of his thoughts is irrational, he will translate ineffectively, unproductive, and suffer from disorder and mismatch. The research objectives of the present study concentrate on the level of irrational thoughts of university instructors as well as detecting the translators' differences between irrational thoughts according to sex variable.

\section{LITERATURE REVIEW}

The degree of translator's personality affects the translation quality when they are under stress and failures. It was found that a decrease in irrational thoughts of the translator's personality makes them highly influential and highly sensitive to blame and criticism, exhibit behavioral disorders when they discover anything unacceptable about themselves [9]. The translator must evade a familiar or unfamiliar problem area arises and develop his or her professional function that they have built up over the years to proceed them through every professional translation consistently [10].

Irrational thoughts are unrealistic ideas that characterized by objectivity and presented a high degree of overestimation of the individual's competencies and negative perception of self and others. Anxiety over a person and on the problems of others with attention maximizes and amplify things because of the individual's cognitive composition. Moreover, the interpretation of events in a manner inconsistent with the potential of the individual studies confirms irrational thoughts role in the emergence of disorders. These ideas come from the accumulations faced by the individual and the pressures in his life and the loss of hope to achieve the real goals, which ultimately leads to the emergence of mental disorders [5].

Kafafi [11] also believes that general psychological weakness, a sense of internal and external threat to the status, objectives of the individual and severe psychological tension, crises or trouble and sudden losses, psychological trauma, guilt, fear of punishment, expectation, a sense of helplessness, lack of return and repression rather than conscious appreciation, which lead to personal injury worry Persistent failure and fear of various sources of threats to try to emerge from reality with irrational thoughts. Highly esteemed people who have not less irrational thoughts are quick to integrate and belong wherever they are. They have enough sense of self-assessment and ability to face the challenge. Studies have shown that these people are better able to control themselves to control their lives and not necessarily think they are better understood. They are not perfect and do not have a magic tool for that, but they are optimistic and realistic with themselves. Hence, the importance of the research is to measure the irrational thoughts of the translators that 
affect their scientific levels. Thus, this study aims at misguided at the level of translators. The translator is one of the segments of the Iraqi society that went through the conditions experienced by Iraqis from the wars and siege and the curse of sectarianism, which lasted more than forty years.

One of the concepts that researchers have studied in recent years is the relationship between translation and psychology that is established in physical, psychological and theoretical techniques. Since the emergence of the work of [12] and other social psychologists who have been used the concept of the translator's personality as a set of personal judgments that the individual sees about himself. As a result of its emotional, mental and physical characteristics, it is closer to the term self-evaluation through its behavioral, emotional, and personal components [13].

Translator's personality is the judgment of the individual on his competence and expresses the individual's attitudes about himself or his beliefs [14]. Translator's personality is also a subjective experience conveyed by the individual to others using different expressive methods [15]. Maslow [16] considers personality as a need to be satisfied when people feel loved and have a sense of belonging, and there is a need for respect. There are two types of respect needs: personality and respect that others give, and satisfying the need for translator's personality allows an individual to feel confident in his strength, value and efficiency and become more capable and productive [15]. In all areas of life, when an individual lacks personality, he is depressed and helpless and lacks sufficient confidence to face problems. Maslow [16] explained that respect and personality to be authentic must remain a realistic assessment of a person's abilities and competence and genuine respect. Two people deserve it from others [17].

All aspects of the personality that characterizes the emotional life (emotional) of the individual and the individual in these aspects put the person distinct from others. The personality refers to the growing sense of pride when the child believes that he can accomplish some things alone without help during the process of socialization in the first three years. Evolution of praesidium vinegar for these seven stages of the development of a gradual and lasts from early childhood to the period in adolescence, and the struggle of self privacy during adolescence all these aspects unite under the term [18]. The fundamental variables associated with translator's personality, which helps to understand and interpret human behavior, and is the result of the interaction of the individual with his environment and because of the importance of the concept of selfdevelopment is one of the objectives [19]. Schiltz [19] says that while the self is fluid, but it is a constant element and an organized unit. Positive personality leads to a sense of satisfaction and a lack of it leads to frustration. As a result, translator's personality comes more positively from within ourselves than from others and becomes a strong need for children to be satisfied and fulfilled in order to maintain it gradually [17]. Life expresses a certain lack of compensation, and is a contribution in this new trend in self-identification, causing significant behavior and contribution to his weight [17]. Narcissism is not true self-love, but rather an exaggeration of the ideal self in its appreciation. We are all - normal and nervous, a self-image and an ideal image of ourselves that may or may not be based on reality. This image is eliminated by the sense of unity and perfection, which is the absolute framework from which it revolves and comes close to ourselves and others in order to reach self-realization, and development to achieve and achieve our potential, our self-image must reflect ourselves to reality (realism), and image with truth be flexible and dynamic change depending on the change of the individual [8].

Ellis [20] asserts that human beings are born with a willingness to act rationally and irrationally. People say they are biologically installed to think twisted on many occasions or to defeat themselves, to exaggerate everything, to feel extreme excitement and to act very strangely for the most trivial reasons. Ready for emotional emotion and mental disorder and then after birth and growth exposed to situations and influences help him to achieve what he has mushroomed, but although Ellis [20] believes that man finds it more comfortable to act childhood, he should not do so. Ellis [20] states that individuals are biologically installed on two types of rational and irrational, describing this by saying that they think crooked on many occasions, or defeat themselves and exaggerate everything and feel excited and behave strangely for the most insignificant reasons, and also have preparations Innate to think efficiently and naturally, they are innovative and learn from their mistakes, and change themselves many times Ellis's [20] theory asserts that the method of rational therapy is one of the most logical therapies because it says that man can accept himself entirely just because he is alive only because he exists, Humans must not assert their value in any way. Man can devise his own goals. He does not need magic or any other to rely on him.

The fundamental part of the emergence of neurological symptoms as [20] sees lies in human nature and their biological and physiological origins and cannot clarify those assets. On the other hand, he believes that the tendency to desire and perfection in the completion of the work at the highest level of mastery almost everyone exists thanks to the innate biological foundations' Individuals attribute their problems and disorders to others and external events [19]. Emotional disorders are based on false temptations. External events are not directly responsible for our mental disorders, but the way we think about them is responsible for disorders [20]. Thinking and his style and types are the results of the interaction between several variables

Irrational thoughts of the translator's personality in assessing the quality of ... (Jabbar Frayyeh Shraida) 
such as the individual's past, previous experience, and ability to education, and the level of culture, and the level of knowledge and social upbringing, cultural factors and civilization and the influence of the surrounding environment [21].

The previous research [20] saw that all ordinary human beings think, feel, and behave as they do so interactively and reciprocally. Their ideas fundamentally affect their feelings and behaviors. The emotions affect their behaviors significantly, and their actions distinctly affect all their thoughts and emotions. To change one of these patterns, changing one of the other two patterns will lead to results. Hence, the full picture of rational, emotional therapy uses cognitive, emotional, and behavioral methods of personality change [8]. A family with irrational function is more likely to fail to deal with the pressures associated with multiple levels in the new stages with other pressures in a rational manner, and that describing the family as unhealthy or satisfactory can contribute to keeping the family in the wrong situation It makes them avoid or resist any discovery of new alternatives. It is the rigid family that behaves irrationally in its functioning and functions. In contrast, the family with intellectual functioning succeeds in adapting to the unavoidable pressures in life in a way that preserves its continuity and coherence.

The concept of irrational thoughts has received the attention of many researchers, as [20] defines it as a set of false and illogical ideas, which are based on a set of false expectations, predictions and generalizations incompatible with the mental potential of the individual. In his theory, Alice defined emotional, behavioral therapy, ideas that he considered irrational, and these ideas are the individual must be loved and accepted by each member of his or her local environment; the individual must be efficient and fully accomplished to have value; some people are evil, so they deserve punishment and blame. It is a serious misfortune that things come contrary to what the individual wishes. Misfortunes and unhappiness are caused by external circumstances that the individual cannot control. Dangerous or frightening things are the causes of great concern and the constant preoccupation of thought. It is easy for an individual to avoid some difficulties and personal responsibilities, rather than face them. The individual must be dependent on others, and there must be someone stronger than him in order to rely on him. Past experiences and events are determined by present-day behavior, and these experiences and events cannot be ignored or excluded. The individual should be upset and saddened by the disorders and problems of others. There is always a perfect and correct solution to every problem, and this solution must be reached otherwise the results become tragic, and this is an irrational idea.

Abdullah [3] notes that Alice identified a set of features that characterize an individual's irrational thoughts that the lack of access to the demands of the individual, and satisfy the desires, cause him emotional disturbances, where he is dominated by the idea that everything he wants must inevitably be achieved. The individual attributes his actions and wrong behaviors to others, which affect his perception of external events, and emotional and behavioral state, and is represented in the continuous blame of the self and others. The individual's irrational thoughts are not derived from the empirical experience that is accurate and honest. External and internal pressures on the individual help in the continuation of the irrational thoughts of the individual unconsciously.

Therefore, the past few years have witnessed an increasing interest in the concept of irrational thoughts. This interest was represented in the emergence of many international and Arab studies that dealt with this concept from different angles such as studies that found a positive correlation between irrational thoughts and depression [6], irrational thoughts and Psychological Stress [4], in the context of the relationship between irrational thoughts and anxiety, a number of studies were conducted. Their results resulted in a statistically significant correlation between irrational thoughts and anxiety, including [2].

Shenawy [4] suggest that high-hopers have a distinction in thinking positively from low-hopers, and also can set their goals and can achieve them, with confidence in their ability, unlike the low-hopers to be able to set goals that fit their abilities. The study of Ibrahim [3] found no differences in the level of irrational thoughts between males and females [3].

Haseeb [9] aimed to identify the prevalence of irrational thoughts. The difference between students for both sexes found that the level of irrational thoughts by $(96.1 \%)$. The idea of predicting disasters to measure irrational thoughts ranked first and followed by the concept of approval, followed by the idea of personal perfection. The study of Ahmad [1] also pointed to the prevalence of irrational thoughts among teachers. The study also showed that the spread of irrational thoughts was more among males. These studies indicate that the prevalence of irrational thoughts among different people. 


\section{RESEARCH METHOD}

In this chapter, the researchers explain the steps and procedures taken in the practical side of this study in terms of methodology, the study sample and the tools used by the study, and the statistical treatments used in the analysis of the test data. In addition, the research limits the university translation instructors and Iraqi translators' association for the academic year 2018-2019.

\subsection{Define terms}

\subsubsection{Irritation thoughts}

Abdullah [3] defines irrational thoughts as false intellectual beliefs built by the individual about himself and the world around him, thus leading to the emergence of emotional and behavioral disturbances of the individual.

\subsubsection{Translation}

The term translation is either the act or the process of converting one's written or speaking language into another language [22]. House [23] assures that that the interest of translation is on how TTs perform in their TL cultures, rather than on textual resemblances between SL and TL [24, 25]. It also includes the process of interpreting any other psychological aspect into another form [26]. Also, Capone and Mey [27] elucidate the consumption of language for the communicative purpose is a social phenomenon which, because of its orientation towards translation, can only be expressed adequately on the level of translation [28]. Göpferich [29] verified that the translation process demands a translation approach to convey the reality of the SL text to the TL text to develop the translation competence in general. The relationship between language and translation can be figured out as figurative representation $[30,31]$.

\subsection{Research community}

The current community consists of 6642 university instructors from the University of Baghdad and Iraqi Translators Association for the academic year 2018-2019, as shown in Table 1. The sample was chosen by simple random technique. The number of respondents was 4649. The applied sample was selected according to [32] table (344) from the research community by (194) males and (150) females. The researcher has neglected the number of professors at the rank of assistant professor, the professorship for research purposes related to age and scientific level that indicate that they are more mature and experienced.

Table 1. The original research community

\begin{tabular}{ccc}
\hline Title & Number by title & Percentage \\
\hline Assistant teacher & 2623 & $39.40 \%$ \\
Teacher & 2026 & $30.50 \%$ \\
Assistant professor & 1350 & $20.30 \%$ \\
Professor & 643 & $9.60 \%$ \\
\hline
\end{tabular}

\subsection{Research tools}

The test of rational and irrational thoughts: Prepared by Rihani [18] and Irrational thoughts as developed by Alice eleven ideas and Rihani added two ideas to fit this scale with the Arab environment, and each idea has four paragraphs on the scale to become the number of paragraphs. The test as a whole is 52 paragraphs, the answer of which is yes first. A value of (2) was given to the response indicating the subject's acceptance of the idea measured by the phrase and (1) to the answer indicating the subject's rejection of the concept. After that, the scale was used by the researcher Abdul Fattah Abdul Qader Mohammed Abu Shireh in 2007 modified by Rihani [18], for the short period the researcher extracted the honesty only to be appropriate for the Iraqi environment where he underwent several arbitrators.

\subsection{Virtual validity}

This type of initial honesty is evident by looking at the paragraphs and knowing what they measure, then matching that with the function to be measured. If the two approaches, the scale is honest, and this type of honesty is achieved when experts examine the scale and then conclude its paragraphs measure what the scale claims to measure. This was achieved by presenting the scale in its initial form to a group of experts in psychology and psychometry. The paragraphs were identical to the Iraqi environment, and there was no change on the scale. 


\section{RESULTS AND DISCUSSION}

To achieve the first objective, which stipulated the recognition of the degree of irrational thoughts for the university instructors, the researchers applied the scale used and corrected the answers and statistically processing the data. The researchers relied on the hypothetical average of the scale to judge the arithmetic average as a cutoff point between males and females. The general average of degrees of irrational thoughts reached 0105.5436 and with a standard deviation of 12.67430. They calculated the significance of the differences between the general average and the hypothetical average of the irrational thoughts scale using the t-test for one sample. It is clear that the difference was statistically significant with a significance level of 0.05 as the $\mathrm{T}$ calculated value is greater than 9.020 scheduling value of 1.283 degree of freedom 352 , as shown in Table 2.

Table 2. The degree of irrational thoughts

\begin{tabular}{ccccccc}
\hline $\begin{array}{c}\text { Number of } \\
\text { individuals }\end{array}$ & $\begin{array}{c}\text { Arithmetic } \\
\text { mean }\end{array}$ & $\begin{array}{c}\text { Standard } \\
\text { deviation }\end{array}$ & $\begin{array}{c}\text { Hypothetical } \\
\text { mean }\end{array}$ & $\begin{array}{c}\text { Calculated } \\
\text { T-value }\end{array}$ & $\begin{array}{c}\text { Tabular } \\
\text { T-value }\end{array}$ & $\begin{array}{c}\text { Significance } \\
\text { level }\end{array}$ \\
\hline 354 & 105.5436 & 12.67430 & 78 & 9.20 & 1.283 & 0.01 \\
\hline
\end{tabular}

This result indicates that there are irrational thoughts of the sample in question and this result coincides with the study of Ahmed [1] in Yemen, which concluded that irrational thoughts are widespread among male and female teachers. Al-Rihani's study [18] in Syria emphasized the spread of irrational thoughts among university students. Maslow [16] indicated the prevalence of irrational thoughts among university students. The arithmetic mean and standard deviations were extracted and T-test was used for two independent samples on the scale of irrational thoughts, as shown in Table 3.

Table 3. The significance of differences in the degree of irrational thoughts in the research sample

\begin{tabular}{ccccccc}
\hline \multicolumn{2}{c}{ Arithmetic mean } & \multicolumn{2}{c}{ Standard deviations } & \multirow{2}{*}{ Value c } & \multirow{2}{*}{ Degree of freedom } & \multirow{2}{*}{ Scheduling function } \\
Males & Females & Males & Females & & & 0.05 \\
\hline 26.28 & 24.58 & 5.362 & 5.103 & 3.25 & 352 & 0.25 \\
\hline
\end{tabular}

The mean of the sample scores (26.28) males and females (24.58) and the number (354) university professors on the scale of irrational thoughts. The standard deviation is (5.362) (5.103) degrees. The test of the differences between the average scores of the male and female sample was used T-test for one sample. The calculated $\mathrm{T}$ value is (3.25) degrees. This shows that the difference is statistically significant at the level of (0.05). The degree of freedom is (352). The difference in favor of the average scores of the male sample is consistent with the study of Ahmed [1] in Yemen where it indicated the existence of statistical differences in the irrational thoughts between teachers according to gender, and in favor of males, Rihani's study [16] indicated a difference between males and females.

This is confirmed by the theory of Ellis [20], who pointed out that sick family can contribute to keeping the family in the wrong situation. To avoid or resist any discovery of new alternatives is the rigid family that behaves irrationally in the performance and functions at a time. When the family succeeds rational functioning in adapting the unavoidable pressures in life, preserving its continuity and cohesion are the critiques that help to identify the rational beliefs.

\section{CONCLUSION}

This study has investigated the role of the translator's personality in identifying the level of irrationality beliefs among university instructors. There are semiotic, linguistic, sociolinguistic, comparative, and interpretive approaches that can help to account for the different linguistic, cultural, and psychological aspects of the act of establishing translation equivalences. Some variables, such as resilience, social support, quality of school life, etc. would best be suited as techniques to be imposed, without losing sight of the overall goals of university training programs. Through the results of this study, it is clear that the importance of rational beliefs in achieving the quality of translation. Thus, the seriousness of irrational thoughts as it is one of the reasons for the incompatibility and its seriousness on the translation.

Based on data analysis that was done, there is a need to pay attention to rational beliefs during the process of socializing and work to refute the irrational thoughts and refute them and replace rational beliefs. Instead, working to develop scientific cadres to discard irrational thoughts through the establishment of educational courses, workshops and curriculum change so that they are able to distinguish between rational 
and irrational, and develop their ability to discard ideas. This leads to the weakness of the quality of their translation work, which caused the distraction of the mind to broadcast the hostile rumor that the enemy managed to exploit confusion in the behavior and irrational thinking of all segments of society, including university professors. The psychological profile of the translator is likely to be of value to recognize his or her weaknesses and strengths, leading to their success and help them develop the quality of their translation work. The researchers recommend that the parents, teachers or psychological guides should refute the irrational thoughts of the children by clarifying the error of these ideas and replacing them with rational ideas. The present study correspondingly suggests studying irrational thoughts for other groups in society and creating awareness programs to get rid of irrational thoughts.

\section{REFERENCES}

[1] A. Abdullah, "Irrational ideas and their Relationship with Psychological Burning among Teachers of Taiz City," Unpublished Master Thesis, Faculty of Education, Sana'a University, Yemen, 2014.

[2] A. Rahman, M. Alsayed, and M. Abdullah, "Irrational thoughts in children and adolescents and their relationship to both the status and characteristic of anxiety and control center," Psychological Studies, vol. 4, no. 3, pp. 415-449, 2014.

[3] A. H. Ibrahim, "The impact of rational therapy to reduce the level of depression in university youth," Unpublished doctoral thesis, Faculty of Education, Zagazig University, 2013.

[4] El-Shenawy, Mohamed Mahrous, "Theories of counseling and psychotherapy," Dar Gharib for printing, publishing and distribution Cairo, 2013

[5] K. W. Mustafa, "The Effectiveness of a Rational Advisory Program to Reduce Stressful Life Events in a Sample of University Students," Psychological Studies, vol. 15, no. 4, pp. 569-598, 2015.

[6] D. Roland, "Method of Psychoanalysis and Freudian Doctrine," Translation of Conservation of Beauty J, Beirut, Arab Foundation for Studies and Publishing.5 - Kamal, Ali (1987) self, emotions and diseases and treatment, Baghdad, Dar Wasit, 2014.

[7] J. Delisle, La traduction raisonnée Manuel d'initiation à la traduction professionnelle de l'anglais vers le français, (3e édition ed.). Ottawa: Les Presses de 1'Université d'Ottawa, 2013.

[8] G. Ramadan, Guidance and psychological counseling, First edition. Dar generation generation Beirut, 2012

[9] A. M. Abdullah Haseeb, "Irrational ideas and their Relationship with the Loneliness and Depression of Secondary and University Students," Journal of Educational Sciences, Institute of Educational Studies (Cairo University), vol. 1, no. 3. pp. 43-73, 2015.

[10] H. A. Ali, "Social Anxiety and its Relationship with Irrational thoughts among Preparatory Students in Public Schools in Gaza Governorate, p. 3, 2013.

[11] A. Kafafi, Family Counseling and Psychotherapeutic Perspective Systemic Communication, First Edition. Cairo Dar Al-Fikr Al-Arabi, p. 324, 2012.

[12] James C. Diggory, Self-evaluation: Concepts and Studies. The University of Michigan, Wiley, 1966.

[13] A. Kafafi, "Self-esteem in relation to parenting and psychological security, a study in the process of self," The Arab Journal of Humanities, vol. 3, no. 5, pp. 316-348, 2013.

[14] Westerheijden, D. F., Stensaker, B., and Joao Rosa, M, Quality Assurance in Higher Education: Trends in Regulation Translation and Transformation. Vol. 20. Dordrecht: Springer, 2007.

[15] H. Lindsey, Theories of Personality, Translated by Faraj and Kadri Hanafi and Lotfi Fatim, Anglo-Egyptian Library, 2016.

[16] Maslow, A. H., Toward a psychology of being. Princeton, NJ: Van Nostrand, 2014.

[17] Huertas-Barros, Elsa, Vandepitte, S., and Iglesias-Fernandez, E, "Quality assurance and assessment practices in translation and interpreting," IGI Global, United States of America, 2019.

[18] S. Rihani, "Irrational thoughts of the Students of the University of Jordan and the Relationship of Sex and Specialization with Irrational Thinking," Dirasat Journal, vol. 14, no. 5, pp. 211-250, 2014.

[19] D. Schiltz, Theories of Personality, translated by Hamad Daly al-Karbouli Abd al-Rahman al-Qaisi. Baghdad University Press, 2016.

[20] Ellis, A., Overcoming resistance: A rational emotive behavior therapy integrated approach, (2nd ed.). New York: Springer, 2007.

[21] Sun, L, "Translation and readers' collective psychology: A macroscopic perspective (Order No. 10473727)," ProQuest Dissertations \& Theses Global, 2011. [Online]. Available: https://search.proquest.com/docview/ 1870684268 ?accountid $=14645$

[22] A. Khuddro, Linguistic Issues and Quality Assessment of English-Arabic Audiovisual Translation. Cambridge Scholars Publishing, UK; 2018.

[23] Juliane House, Translation quality assessment: past and present. Routledge, Taylor \& Francis Group, New York, 2015.

[24] Colina, S, Fundamentals of Translation. Cambridge: Cambridge University Press, 2015.

[25] Hebenstreit, Gernot, "Defining patterns in Translation Studies," Target, vol. 19, no. 2, pp. 197-215, 2007.

[26] Bielsa, Esperança, "Cosmopolitanism as Translation," Cultural Sociology, vol. 8, no. 4, pp. 392-406, 2014.

[27] Capone, Alessandro and Mey, Jacob L, Interdisciplinary Studies in Pragmatics, Culture and Society. Switzerland: Springer International Publishing, 2016. 
[28] Merkle, D, "Compte rendu de," in A. Pym, M. Shlesinger and Z, Jettmarová Ed., Sociocultural Aspects of Translating and Interpreting. Amsterdam/Philadelphia, John Benjamins Publishing Company, vol. 19, no. 2, pp. 255-258, 2006.

[29] S. Göpferich, "Towards a model of translation competence and its acquisition: the longitudinal study TransComp," In S. Göpferich, A. L. Jakobsen and I. M. Mees (eds), Behind the Mind: Methods, Models and Results in Translation Process Research. Copenhagen: Samfundslitteratur, pp. 11-37, 2009

[30] Lörscher, W., "Bilingualism and translation competence," SYNAPS-A Journal of Professional Communication, vol. 27, pp. 3-15, 2012. [Online]. Available: http://hdl.handle.net/11250/2393971

[31] T. Mahadi, T. Sepora and M. Mohamed, Text- wise in translation. Malaysia Pearson Malaysia Sdn. Bhd, 2006.

[32] Krejcie, RV. and Morgan, DW., "Determining sample size for research activities," Educational and psychological measurement, vol. 30, no. 3, pp. 607-610, 1970. 